\title{
Numerical simulations of wind-driven rain on an array of low-rise cubic buildings and validation by field measurements
}

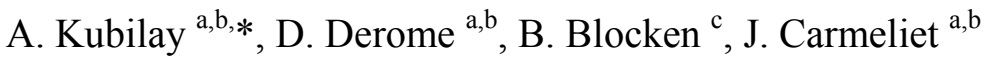 \\ ${ }^{a}$ Chair of Building Physics, Swiss Federal Institute of Technology ETHZ, Zurich, Switzerland \\ ${ }^{b}$ Laboratory for Building Science and Technology, Swiss Federal Laboratories for Materials Science and Technology \\ EMPA, Dübendorf, Switzerland \\ ${ }^{c}$ Building Physics and Services, Eindhoven University of Technology, Eindhoven, The Netherlands \\ ${ }^{*}$ Corresponding author: Aytac Kubilay, Institute of Technology in Architecture, Chair of Building Physics, ETH Zurich, \\ Wolfgang-Pauli-Strasse 15, CH-8093, Zurich, Switzerland. Tel.: +41 58765 4276; E-mail address: kubilay@arch.ethz.ch
}

\begin{abstract}
The relation between wind-driven rain (WDR) and its potential negative effects on the hygrothermal performance and durability of building facades can be better understood by the correct estimation of the spatial and temporal distribution of the WDR intensity. Computational Fluid Dynamics (CFD) simulations with Eulerian Multiphase (EM) modeling are used to obtain accurate spatial and temporal information on WDR. The EM model has the advantage of predicting the WDR intensity on all surfaces of a complex geometry within the domain at once. There is a lack of numerical studies on the WDR intensity in generic and idealized multi-building configurations. In this paper, WDR intensities on an array of 9 low-rise cubic building models for wind from three different wind directions are estimated numerically using the EM model including the turbulent dispersion of raindrops. The numerical results are validated by comparing the calculated catch ratio values with data from field measurements in Dübendorf, Switzerland after two rain events with different characteristics. The CFD simulations successfully estimate the WDR intensities at the positions of 18 WDR gauges for both rain events. The influence of turbulent dispersion is found to be lower than 3\% for both rain events. It is found that, for oblique wind directions, even though the maximum WDR intensity on the facades is lower, the whole building is exposed to up to $57 \%$ more WDR.
\end{abstract}

Keywords: Wind-driven rain, Validation, Computational fluid dynamics (CFD), Eulerian multiphase model, Turbulent dispersion

\section{Introduction}

Wind-driven rain (WDR) is rain with a horizontal velocity component due to its co-occurrence with wind. WDR is one of the most important moisture sources that influence the hygrothermal performance and the durability of building facades. It can lead to several undesired phenomena in building physics such as frost damage at exterior wall surfaces [1-3], erosion of building materials $[4,5]$, moisture induced salt migration $[2,6]$, discoloration by efflorescence [2], surface soiling [7, 8] and mold growth at interior wall surfaces [9].

Three methods exist for estimating the WDR intensity on building surfaces: (1) measurements, (2) semi-empirical methods and (3) numerical simulations with Computational Fluid Dynamics (CFD). Blocken and Carmeliet [10, 11], Blocken et al. [12] and Blocken [13] provided extensive reviews of WDR research in building physics. Generally, measurements of WDR on building facades are difficult, time-consuming and prone to errors [14-16]. They are also confined to the meteorological conditions present at the time of experiments. Semi-empirical methods, on the other hand, are fast and easy to use but they only give approximations of the WDR intensity and they cannot provide detailed information. The impinging WDR intensity is governed by several parameters, such as building geometry, environment topography, position on the building facade, wind speed, wind direction, rainfall intensity and raindrop-size distribution [17]. The semi-empirical methods are unable to reliably take all of these effects into account $[3,14,18]$. Therefore, semi-empirical methods are generally suitable only for stand-alone buildings in simple configurations, or for preliminary analysis. CFD simulations have the advantage of providing detailed spatial and temporal WDR distributions on complex building geometries. Furthermore, CFD simulations can give detailed information on the rain drop impact speed and impact angle on the facade, which can later be used to determine the droplet physics after impact, such as bouncing, splashing, spreading and film forming. These phenomena are particularly important to distinguish in building envelope heat-air-moisture (BE-HAM) transport models, where WDR intensity is used as a main boundary condition [12, 19-21]. 
A steady-state numerical simulation technique for WDR was developed by Choi [22-25] by combining the ReynoldsAveraged Navier-Stokes (RANS) equations and Lagrangian Particle Tracking (LPT). Several researchers applied similar models with LPT $[8,17,26-34]$ on isolated buildings or on particular buildings in a geometrically complex environment. Blocken and Carmeliet [17] extended Choi's simulation technique by adding the temporal component, allowing the determination of both the spatial and temporal distribution of WDR for transient rain events. Huang and Li [35] showed that the Eulerian Multiphase (EM) model with RANS can give accurate results for WDR on the windward facade of an isolated low-rise building. Kubilay et al. [36] performed a validation study with the EM model on a historical building with a monumental tower by comparing the results with measurement data and with numerical data from the LPT model. This study showed that the user time spent for the simulation of WDR on an isolated building decreases by at least a factor of 10 using the EM model compared to the LPT model. The turbulent dispersion of raindrops was implemented into the Eulerian Multiphase (EM) model for the mean WDR calculations by Kubilay et al. [37]. It was shown that taking turbulent dispersion into account reduces the deviation between CFD simulations and field measurements for a high-rise tower building.

In the present paper, a CFD validation study is performed on an array of low-rise cubic building models. CFD simulations using the EM model with turbulent dispersion of raindrops are performed to study the WDR intensity during two rain events. The validation of the numerical model is accomplished by comparing the results with the WDR measurement dataset provided by Kubilay et al. [3]. Section 2 presents the field measurement geometry and the measured rain event data for the validation study. In section 3, the numerical model, the governing equations, the computational domain, the boundary conditions and the solver settings are described. Section 4 presents the results of the CFD simulations, the validation study and analysis of WDR on building models. Finally, sections 5 and 6 provide a general discussion and conclusion, respectively.

\section{Field measurements}

The measurement setup is composed of 9 identical low-rise cubic building models. They are positioned in a regular array as shown in Fig. 1. The building models each have dimensions $\mathrm{H} \times \mathrm{H} \times \mathrm{H}=2 \times 2 \times 2 \mathrm{~m}^{3}$ and they are spaced $\mathrm{H}=2 \mathrm{~m}$ apart. The total height of the models, with the wooden support beams below, is $2.17 \mathrm{~m}$. The measurement setup is located on the campus of the Swiss Federal Laboratories for Materials Science and Technology (Empa) in Dübendorf in a suburban area located east of the city of Zurich, Switzerland, latitude $47^{\circ} 24^{\prime} 9^{\prime \prime}$ and longitude $8^{\circ} 36^{\prime} 50^{\prime \prime}$. The field measurements were performed between May 2013 and October 2013. A detailed description of the building and environment geometry and of the measurement results can be found in Kubilay et al. [3].

The WDR measurements are conducted on the west facades of cubes 2 and 8, indicated in grey in Fig. 1(a). These facades are instrumented with 9 WDR gauges each. The collectors of the WDR gauges are connected via tubing to tipping bucket mechanisms that are placed inside the building models. The reference measurements of wind speed and wind direction are conducted at a meteorological mast, located $3 \mathrm{H}(=6 \mathrm{~m})$ west of the array of cubes. The horizontal rainfall intensity is measured by a rain gauge with tipping bucket mechanism positioned near the meteorological mast.

Fig. 2 shows two rain events that were measured on June 9-10, 2013 and September 16-19, 2013 [3]. The most important sources of measurement errors are the evaporation of adhesion water, $E_{A W}$, and the rest-water in the tipping bucket, $E_{R W}$. The relative errors, $E_{T O T}=\left(E_{A W}+E_{R W}\right) / S_{w d r}$, where $S_{w d r}$ is the total WDR amount registered by a WDR gauge during a rain event, are estimated (following the procedure in [3]) to be between $2.2 \%$ and 3.9\% for the rain event on June 9-10, 2013 and between $14.8 \%$ and $34.2 \%$ for the rain event on September 16-19, 2013. The rain events with low measurement errors were selected for CFD validation in this study.

\section{Numerical simulation}

In the EM model, the rain phase is regarded as a continuum as is the air phase. Each class of raindrop size is treated as a different phase, as each group of raindrops with similar size will interact with the wind-flow field in a similar way.

\subsection{Governing equations}

In the present study, the wind-flow equations are solved using 3D steady RANS with the renormalization group (RNG) $k-\varepsilon$ model [38]. Rain phase calculations are one-way coupled with the air phase. This is a valid assumption as the volumetric ratio of rain in air is below $1 \times 10^{-3}$ for rainfall intensities up to $20 \mathrm{~mm} / \mathrm{h}$ and below $1 \times 10^{-2}$ for even the most severe cases according to the study by de Wolf [39] that provides the distribution density of raindrop diameters at different rainfall intensities. For each rain phase, the following continuity and momentum equations are solved separately: 
$\frac{\partial \alpha_{k}}{\partial t}+\frac{\partial\left(\alpha_{k} \bar{u}_{k, j}\right)}{\partial x_{j}}=0 \quad$ (no summation over $k$ )

$\frac{\partial \alpha_{k} \bar{u}_{k, i}}{\partial t}+\frac{\partial\left(\alpha_{k} \bar{u}_{k, i} \bar{u}_{k, j}\right)}{\partial x_{j}}+\frac{\partial\left(\alpha_{k} \overline{u_{k, i}^{\prime} u_{k, j}^{\prime}}\right)}{\partial x_{j}}=\alpha_{k} g+\alpha_{k} \frac{3 \mu_{a}}{\rho_{w} d^{2}} \frac{C_{d} \operatorname{Re}_{R}}{4}\left(\bar{u}_{i}-\bar{u}_{k, i}\right) \quad$ (no summation over $k$ )

where $d$ denotes the raindrop diameter, $\alpha_{k}$ the phase fraction of rain phase $k, u_{i}$ the velocity component of wind in direction $i, u_{k, i}$ the velocity component of $k^{\text {th }}$ phase of rain, $\rho_{w}$ the density of the raindrops, $\mu_{a}$ is the air dynamic viscosity, $g$ the gravitational acceleration and $C_{d}$ the drag coefficient. The overbar denotes Reynolds averaging. In Eq. 2, the terms on the left hand are the transient term, the mean momentum flux and the turbulent momentum flux. The terms on the right hand side represent the gravity and the drag forces. $\operatorname{Re}_{R}$ denotes the relative Reynolds number and is calculated as:

$\operatorname{Re}_{R}=\frac{\rho_{a} d}{\mu_{a}}\left\|\vec{u}-\overrightarrow{u_{k}}\right\|$

where $\rho_{a}$ denotes the density of the air, $\vec{u}$ the air phase velocity vector, and $\overrightarrow{u_{k}}$ the rain phase velocity vector. The Reynolds stresses in the rain phase momentum equation are modeled according to the Boussinesq eddy-viscosity approximation [40]:

$-\overline{u_{k, i}^{\prime} u_{k, j}^{\prime}}=v_{t, d}\left(\frac{\partial \overline{u_{k, i}^{\prime}}}{\partial x_{j}}+\frac{\partial \overline{u_{k, j}^{\prime}}}{\partial x_{i}}-\frac{2}{3} \frac{\partial \overline{u_{k, k}^{\prime}}}{\partial x_{k}} \delta_{i j}\right)-\frac{2}{3} k_{d} \delta_{i j}$

where $v_{t, d}$ denotes the turbulent kinematic viscosity of the rain phase, $k_{d}$ the turbulence kinetic energy of the rain phase and $\delta_{i j}$ the Kronecker delta. The Boussinesq approximation relates the Reynolds stresses to the mean shear rate by the turbulent viscosity. The turbulent kinematic viscosities of the wind phase and the rain phases are related as shown in Eqs. (5-7).

$$
\begin{aligned}
& \frac{v_{t, d}}{v_{t, a}}=\frac{1}{1+\frac{t_{p}}{t_{f l}}} \\
& t_{p}=\frac{4 \rho_{w} d^{2}}{3 \mu_{a} C_{d} \operatorname{Re}_{R}} \\
& t_{f l} \cong 0.2 \frac{k}{\varepsilon}
\end{aligned}
$$

where $v_{t, a}$ denotes the turbulent kinematic viscosity of the air phase, $t_{p}$ the particle relaxation time and $t_{f l}$ the Lagrangian fluid time scale, $k$ the turbulence kinetic energy of air phase and $\varepsilon$ the turbulence dissipation rate of the air phase. The particle relaxation time is defined as the rate of response of particle acceleration to the relative velocity between the particle and the carrier fluid. The Lagrangian fluid time scale can be viewed as the characteristic large eddy lifetime. For detailed information on the turbulent dispersion modeling of WDR the reader is referred to Kubilay et al. [37].

\subsection{WDR parameters}

The WDR intensity is related to the unobstructed horizontal rainfall intensity by the specific catch ratio, $\eta_{d}(k)$, and the catch ratio, $\eta$. The specific catch ratio is related to the rain phase $k$. The catch ratio is related to the entire spectrum of raindrop diameters. The quantities of the WDR parameters can be obtained after solving the governing equations in Eqs. (1-2) by using the following relations:

$$
\eta_{d}(k)=\frac{R_{w d r}(k)}{R_{h}(k)}=\frac{\alpha_{k}\left|V_{n}(k)\right|}{R_{h} f_{h}(k)}
$$


$\eta=\int_{d} f_{h}\left(R_{h}, d\right) \eta_{d} \mathrm{~d} d$

where $R_{w d r}$ denotes the WDR intensity, $R_{h}$ the horizontal rain intensity through the horizontal plane, $f_{h}\left(R_{h}, d\right)$ the raindropsize distribution through the horizontal plane [10] and $\left|V_{n}(k)\right|$ the velocity magnitude of the rain phase in the direction normal to the building facade.

In the present study, the raindrop-size distribution through the horizontal plane (see Fig. 3) is adopted from Best [41], whose results are based on a wide bibliographical survey and measurements for a large number of rain events at various locations.

\subsection{Computational domain}

Fig. 4 shows the computational domains for wind directions northwest, west and southwest based on the geometry for the field measurements shown in Fig. 1(a). For an accurate study, the flow profiles should be horizontally homogeneous because the inlet profiles actually correspond to the measured data obtained at a location close to the building. However, several researchers [42-47] reported the occurrence of unintended streamwise gradients in the vertical flow profiles (or horizontal inhomogeneity) due to the inconsistencies between the inlet boundary conditions, the wall boundary conditions, the surface roughness modeling and the computational grid. If the computational domain in Fig. 4(b) is also used for oblique wind directions, the approach flow on one side accelerates more due to the unequal distances from the inlet, resulting in an unintended non-symmetric flow field. Thus, separate computational domains were prepared for each wind direction, so that the distances of the cubes from both inlet boundaries for oblique wind directions are equal. Richards and Hoxey [47] and Blocken et al. [43] provided remedial measures against horizontal inhomogeneity, e.g. minimization of upstream domain length or artificial reduction of turbulent kinetic energy. Artificial reduction of turbulence kinetic energy should be avoided because it can change the size of separation regions. Therefore, the upstream distance of the cubes from the inlet is decreased to $3 \mathrm{H}=6 \mathrm{~m}$. The remaining boundary distances satisfy the guidelines stated in Tominaga et al. [48] and Franke et al. [49].

For the grid-sensitivity analysis, three structured and purely hexahedral grids are created. The base grid consists of $1,341,662$ cells. The coarse grid has 717,840 cells whereas the fine grid has $2,636,980$ cells. The first cell height on the ground and building surfaces has been kept constant $(0.015 \mathrm{H}$ for ground and $0.005 \mathrm{H}$ for building surfaces) for each grid in order to keep the dimensionless wall distance $y^{+}$the same. The average $y^{+}$value is 60 on the ground and 25 on the building surfaces. The grid-sensitivity analysis was conducted by comparing the magnitude of the wind velocity along two vertical lines from the ground up to a height of $1.5 \mathrm{H}$ and one horizontal line. The vertical lines are positioned at $0.05 \mathrm{H}$ upstream and $0.05 \mathrm{H}$ downstream of cube 2 and the horizontal line is positioned at $0.05 \mathrm{H}$ above the rooftop of cube 2 , all in the centerplane, as shown in Fig. 5. $U_{\text {ref }}$ denotes the reference wind speed of $1 \mathrm{~m} / \mathrm{s}$ at $2.4 \mathrm{~m}$ height. No large differences are observed between grids along the lines and almost all points are within the $10 \%$ deviation lines. The maximum difference is $10.9 \%$ between coarse and base grids and $4.0 \%$ between base and fine grids. As a result, the base grid is chosen for the rest of the study. The base computational grid on the buildings and on part of the ground surface is shown in Fig. 6.

\subsection{Boundary conditions}

The inlet profile of mean wind speed is given by the typical log-law expression:

$U(y)=\frac{u^{*}{ }_{A B L}}{\kappa} \ln \left(\frac{y+y_{0}}{y_{0}}\right)$

where $U(y)$ denotes the mean streamwise wind speed at height $y$ above the ground plane, $u_{A B L}$ the atmospheric boundary layer (ABL) friction velocity, $\kappa$ the von Karman constant ( 0.42 in the present study) and $y_{0}$ the aerodynamic roughness length. The approach wind profiles are measured by the meteorological mast, which is positioned $6 \mathrm{~m}$ away from the array of cubes [3]. The inlet mean wind speed profiles are characterized by, for wind from west and southwest, $u^{*}{ }_{A B L} / U=0.24$ and $y_{0}=0.49 \mathrm{~m}$, and for wind from northwest, $u^{*}{ }_{A B L} / U=0.34$ and $y_{0}=1.02 \mathrm{~m}$. The inlet profiles of the turbulent quantities $k$ and $\varepsilon$ are defined by Eqs. (11) and (12), where $I_{u}$ denotes the streamwise turbulence intensity. The turbulence intensity is taken $30 \%$ at $y=2 \mathrm{~m}$ height, $8 \%$ at gradient height for southwest and west wind and $40 \%$ at $y=2 \mathrm{~m}$ height, $10 \%$ at gradient height for northwest wind.

$k(y)=\left(I_{u} U(y)\right)^{2}$ 


$$
\varepsilon(y)=\frac{u^{*}{ }_{A B L}^{3}}{\kappa\left(y+y_{0}\right)}
$$

For wall treatment, the standard wall functions by Launder and Spalding [50] with sand-grain roughness modification [51] are used. The equivalent sand-grain roughness height, $k_{s}$, and the roughness constant, $C_{s}$, are determined by the following relation by Blocken et al. [43] which is valid for the wall function in OpenFOAM:

$k_{s}=\frac{E y_{0}}{C_{s}}$

where $E$ is an empirical constant with a value of 9.793. In the computational domain, the ground surface represents the asphalt parking lot in Fig. 1(b). For the ground surface of the computational domain, $k_{s}$ is taken to be $0.005 \mathrm{~m}$ and $C_{s}$ is set as 9.793 , leading to an aerodynamic roughness length $y_{0}=0.005 \mathrm{~m}$, representing a featureless land surface without any noticeable obstacles [52]. Note that the above-mentioned higher values of $y_{0}$ represent the ground surface beyond (i.e. upstream of) the computational domain. The building surfaces are assumed to be smooth $\left(k_{s}=0\right)$.

For the top boundary, constant values are set for $U, k$ and $\varepsilon$ by using fixed values from the inlet profiles at the same height as suggested by Blocken et al. [43], e.g. $U_{\text {top }}=U_{\text {inlet }}(y=12 \mathrm{~m})$. This is done in order to limit the horizontal inhomogeneity, as other top boundary conditions, such as symmetry condition, can cause streamwise gradients. Although imposing constant values does not allow fluid to enter or exit the domain, the top boundary is far enough from the buildings not to cause a problem. A constant static gauge pressure of $0 \mathrm{~Pa}$ is used at the outlet boundary. This boundary condition at the outlet implies a fully developed flow at the outlet and should not interfere with the results as long as the outlet boundary is placed away from the influence by the buildings (15H distance [49], see Fig. 4). Note that this gauge pressure is relative to reference atmospheric pressure. Symmetry conditions are applied on both sides of the domain for wind from west. For the domains for the wind from southwest and northwest, the side domains are set as inlet and/or outlet.

With the definitions established in section 3.2, the volumetric ratio of rain phase $k, \alpha_{k}$, can be calculated as in Eq. (14), where $V_{t}(d)$ represents the terminal velocity of a raindrop with diameter $d$.

$\alpha_{k}=\frac{R_{h} f_{h}\left(R_{h}, d\right)}{V_{t}(d)}$

The terminal velocity measurements were made by Gunn and Kinzer [53] and shown in Fig. 7. The value of volumetric ratio of each rain phase, $\alpha_{k}$, is imposed at the inlet and top boundaries. For the rain phase velocity, $u_{k}$, it is assumed that the boundaries are undisturbed and far away from the building in the domain. The vertical inlet rain phase velocity component is set equal to the terminal velocity for that phase. The horizontal inlet rain phase velocity components are set equal to the air phase velocity components, so that the relative velocity between wind and rain is zero at the boundary.

The boundary conditions for the rain phases at the building walls, on the ground and at the outlet are set in such way that the normal gradient of the volumetric ratio, $\partial \alpha_{k} / \partial n$, equals zero when the normal wind velocity vector is pointing out of the domain, and the values of the volumetric ratio, $\alpha_{k}$, are equal to zero when the normal wind velocity vector is pointing into the domain. With these boundary conditions, the interaction between the raindrops and the walls are not modeled and the raindrops leave the domain as soon as they hit a wall boundary, avoiding any inflow of rain phase into the domain due to possible recirculation regions.

\subsection{Solution strategy}

The methodology is similar to the Choi's steady-state WDR approach $[23,24]$ that was extended into the time domain by Blocken and Carmeliet $[17,54]$. It consists of the following steps:

a. The steady-state wind flow field around the buildings is calculated for the reference wind speed $U=1 \mathrm{~m} / \mathrm{s}$ and the reference wind directions southwest $\left(\varphi=225^{\circ}\right)$, west $\left(\varphi=270^{\circ}\right)$ and northwest $\left(\varphi=315^{\circ}\right)$. The wind flow field for other values of reference wind speed $(U=2,3,5 \mathrm{~m} / \mathrm{s})$ are obtained by linear scaling. Such scaling is allowed for flows around sharp-edged bluff bodies, where the positions of flow separation are independent of the Reynolds number.

b. The turbulent viscosity, $v_{t}$, is scaled linearly for the reference wind speed values, $U=1,2,3,5 \mathrm{~m} / \mathrm{s}$. Similarly, the turbulence kinetic energy, $k$, is scaled quadratically and the turbulence dissipation rate, $\varepsilon$, is scaled cubically. In fact, for 
fully turbulent flow, the turbulence statistics have only a weak dependence on Reynolds number [55]. Wind tunnel measurements by Defraeye [56] for flows around bluff bodies show limited Reynolds number dependency at $\operatorname{Re}>10^{4}$, calculated with reference wind speed and building height.

c. The governing equations for the rain phases are solved and specific catch ratio distributions are calculated for several raindrop diameters (diameters ranging from 0.3 to $1 \mathrm{~mm}$ in steps of $0.1 \mathrm{~mm}$, from 1 to $2 \mathrm{~mm}$ in steps of $0.2 \mathrm{~mm}$ and from 2 to $6 \mathrm{~mm}$ in steps of $1 \mathrm{~mm})$.

d. Catch ratio distributions are obtained for reference horizontal rainfall intensities of $R_{h}=0,0.1,0.5,1,2,3,4,5,6,8,10$, $12,15,20,25$ and $30 \mathrm{~mm} / \mathrm{h}$ using the droplet-size distribution as input for each reference wind speed and wind direction. Note that the cubes influence the wind-flow pattern at the meteorological mast for wind directions such as southeast, east and northeast [3]. Thus, the catch ratio values for wind directions between $\varphi=0^{\circ}-180^{\circ}$ are not calculated and assumed zero on the west facades of the cubes.

e. The calculated catch ratio values are interpolated based on the experimental data records for wind speed, wind direction and horizontal rainfall intensity at each 10-min experimental time step during a certain rain event to obtain the spatial and temporal distributions of WDR on the building facades.

\subsection{Solver settings}

OpenFOAM ${ }^{\circledR} 2.2$ [57] is used in this study as the CFD code. It is an open-source, implicit, segregated, and double precision solver. An additional solver has been implemented into the code by the authors for solving the governing equations of the rain phases. This solver gives the rain phase velocity, volumetric ratio and specific catch ratio distributions in a one-way coupled fashion.

The pressure-velocity coupling for the wind-flow field solution is taken care of with the Semi-Implicit Method for Pressure Linked Equations (SIMPLE) algorithm. Second-order discretization schemes are used for both the convection terms and the viscous terms of the governing equations. For both the air and rain phase calculations, the simulations were terminated when all the scaled residuals reached $10^{-6}$.

\section{Results}

\subsection{Flow patterns}

Fig. 8(a) shows the streamlines of mean wind velocity and the contours of magnitude of mean wind velocity in the vertical centerplane for the wind from west. The standing vortex in front of cube 2 and the recirculation regions between cubes 2-5 and 5-8 and behind cube 8 are visible. There is a thin separation zone on top of cube 2 with a reattachment point located on the rooftop, at about $1 / 3 \mathrm{H}$ downstream. Fig. 8(b) and (c) show the streamlines of mean wind velocity and the contours of magnitude of mean wind velocity projected onto a horizontal plane at $y=1 \mathrm{~m}$ for wind from west and southwest, respectively. Note that Fig. 8(b) and (c) do not include the out-of-plane component of the velocity and hence do not represent the full streamlines of a 3D flow, but they allow for a clear visualization. In Fig. 8(b), the flow is accelerated around the outer edges of the array of cubes, as well as in the passages between the rows of buildings. In the passages, the wind speed is higher between cubes 1-2 and 2-3 than it is between the others. There are separation zones at the side edges of cubes 1-3. The approach wind speed in the upstream of the first row of cubes is higher compared to what occurs for the rest of the cubes. The regions between the cubes have recirculation zones of low wind speed. Behind the cubes 2,5 and 8 , the pair of vortices in the mean wind-flow pattern are symmetric, on the other hand, the mean wind-flow pattern is nonsymmetric behind the rest of the cubes. In Fig. 8(c), with southwest wind direction, the wind flow pattern has a more complex structure. The main flow direction switches between the cubes depending on the position. Moreover, high wind speed regions with flow directions parallel to the facades exist around the further edges of the cubes. At the separation regions, recirculation zones of low wind speed are present. The wind directions in front of the west facades of the cubes 2 and 8 are mostly parallel to the facades and wind flows from south.

Fig. 9(a) and (b) show the rain phase streamlines passing through two vertical lines at the inlet with droplets moving in the direction indicated by the red line (wind from west). The streamlines are for raindrop size $d=0.3 \mathrm{~mm}$, reference wind speed of $U=3 \mathrm{~m} / \mathrm{s}$ and reference wind direction $\varphi=270^{\circ}$. In Fig. 9(a), in front of the cubes 5 and 8, the droplets move away from the facade in a similar way up until $2 / 3 \mathrm{H}$ height. Note that in Fig. 8 (a), between cubes $2-5$ and $5-8$, the flow patterns and wind speed values are quite similar. On the other hand, the streamlines hit the facade of cube 2 with angles closer to the normal. In Fig. 9(b), the streamlines move away from the facade of the cube 2 due to strong acceleration of the wind flow around the side edge, whereas they hit the facades of the cubes 5 and 8. Fig. 9(c) and (d) show the rain phase streamlines passing through two vertical lines at the inlet with droplets moving in the direction indicated by the red line (wind from southwest). The streamlines are for raindrop size $d=0.3 \mathrm{~mm}$, reference wind speed of $U=3 \mathrm{~m} / \mathrm{s}$ and reference wind 
direction $\varphi=225^{\circ}$. The effect of the recirculation regions is also clear in Fig. 9(c). In Fig. 9(d), the droplets move in a complex manner in different directions depending on the local flow field.

Fig. 10(a) and (b) show the catch ratio charts on the west facades of cubes 2 and 8 for reference wind direction $\varphi=270^{\circ}$ at the top edge and at the center, respectively. Catch ratio charts give the catch ratio at a certain position for different combinations of reference wind speed, reference wind direction and reference rainfall intensity. The WDR intensity values at the top of the facades are very close to each other for each couple of reference wind speed and reference rainfall intensity. On the other hand, in Fig. 10 (b), the difference in catch ratio due to the influence of the local wind flow field is clear. The lower part of cube 8 is exposed to less rain. The difference between the two cubes is getting larger as the reference rainfall intensity decreases because there are more smaller raindrops. Smaller raindrops have smaller inertia and, thus, they are more easily moved away from the facade by the wind. The difference in catch ratio values increases also with increasing reference wind speed, as the recirculation region is getting stronger at higher reference wind speed values.

\subsection{Validation of the numerical model}

Fig. 11(a) shows the measured catch ratio values by the WDR gauges on the west facades of the cubes 2 and 8 at the end of the rain event on June 9-10, 2013 [3]. Fig. 11(b) shows the numerical estimation of the WDR intensity. The positions of the WDR gauges are indicated by squares and the values are surface averaged over the area of the WDR gauges. The numerical model generally estimates the catch ratios quite well, the deviations being up to $6.5 \%$ at the top and up to $11.1 \%$ at the bottom of the cube 2 . The average discrepancy is $5.2 \%$. The cube 8 shows discrepancies of up to $4.6 \%$ at the top and up to $18.0 \%$ at the bottom of the facade. The average discrepancy is $5.4 \%$. The discrepancies are higher at the bottom of the facade due to less WDR registered, leading to relatively higher adhesion-water evaporation error [3]. Fig. 11(c) compares the measured and the numerical cumulative WDR amounts for the WDR gauges in the middle of the facades during the rain event. The numerical estimation for the cumulative WDR follows the recorded amount of WDR very well.

Fig. 12(a) shows the measured catch ratio values by the WDR gauges on the west facades of the cubes 2 and 8 at the end of the rain event on September 16-19, 2013 [3]. Fig. 12 (b) shows the numerical estimation of the WDR intensity. The deviations are up to $9.9 \%$ at the top and up to $15.6 \%$ at the bottom of the cube 2 . The average discrepancy is $6.5 \%$. The cube 8 shows discrepancies of up to $6.8 \%$ at the top and up to $34.9 \%$ at the bottom of the facade. The average discrepancy is $12.0 \%$. The experimental error in this rain event is higher than in the first one due to higher adhesion-water evaporation that occurs during the frequent interruptions of this rain event [3]. Note that the experimental errors are mostly negative errors, as evaporation of water is not registered. Fig. 12(c) compares the measured and the numerical cumulative WDR amounts for the WDR gauges in the middle of the facades during the rain event. The numerical values mostly follow the experimental data accurately until the last part of the rain event, where there are many short durations of rain with spikes of high rainfall intensity.

The influence of turbulent dispersion on the catch ratio is quantified by solving the rain phase equations also once without the Reynolds stress term (third term on the left hand side in Eq. 2). Note that, with this simplification, the rain phase momentum equation becomes equivalent to the ones used in several studies in the literature that neglect turbulent dispersion of raindrops [17, 18, 23, 24, 31, 32, 35]. For both rain events, the influence of turbulent dispersion is found to be up to $3 \%$ for cubes 2 and 8. Kubilay et al. [37] discussed that the influence of turbulent dispersion is dependent on the reference wind speed and reference rain fall intensity, hence dependent on the conditions during the rain event. Furthermore, the influence of turbulent dispersion is expected to be higher for a wider and higher building compared to a low-rise cubic building, as the turbulence kinetic energy would be higher compared to the value at $y=2 \mathrm{~m}$ height.

\subsection{Analysis of WDR simulation results}

Fig. 13 shows the catch ratio on the surfaces of all cubes for a reference wind speed of $5 \mathrm{~m} / \mathrm{s}$ and a reference rainfall intensity of $1 \mathrm{~mm} / \mathrm{h}$ for reference wind directions west and southwest. In Fig. 13(a), as also seen in Fig. 10(a), the catch ratio values for all cubes are very close to each other at the top of the cubes. However, at the lower half of the facade, there is a clear difference between the cubes in the front row and the ones at the back. Especially for wind from west, the cubes at the back have larger gradients on their west facades. Furthermore, the effect of the non-symmetric single vortex regions in front of the cubes 4 and 6 for wind from west (see Fig. 8(b)) is visible on the catch ratio distributions of those cubes in Fig. 13(a). For those cubes, the catch ratio distributions are non-symmetric on their west facades. At the lower part of cube 6 , the catch ratio is less on the right side of the west facade due to the streamlines moving away from the facade at that position. On the rooftops, the catch ratio values are very close to 1 except the front parts of the roofs of cubes 1-3. In Fig. 13(b), overall, the catch ratio distribution seems to be more homogeneous on the facades of the cubes compared to the results for the wind 
from west. There is a difference in catch ratios at the lower parts of the cubes, but the difference is not as clear as in Fig. 13(a).

Fig. 14 compares the surface averaged catch ratio on different facades of all cubes for wind from west and southwest. For wind from west (Fig. 14(a)), the cubes in the front row have about 30\% higher WDR on average on their west facades compared to the cubes at the back. There is limited amount of WDR on the south and north facades. East facades of the cubes are subjected to very little WDR. Cube 5 particularly is subjected to the least amount of WDR. For wind from southwest (Fig. 14(b)), the west facades of all cubes are subjected to less WDR on average as well as smaller WDR gradient on their facades (see Fig. 13(b)). On the other hand, for wind from southwest, cubes 1-3 are exposed to up to 34\% more WDR and the cubes 4-9 are exposed to up to 57\% more WDR on their facades in total compared to wind from west. This is mainly due to larger cross sectional area of the buildings with oblique wind direction to the building orientation. However, the extent of this effect is different for each building position. Wind from southwest leads to WDR on the west and south facades of the buildings to be almost equal. Cube 5 is subjected to the least amount of WDR.

\section{Discussion}

Previously, the WDR intensity results of the implemented EM model were compared with the existing numerical and experimental studies on a high-rise tower building [36]. On the same building, Kubilay et al. [37] showed that the turbulent dispersion modeling decreases the discrepancy between the numerical and experimental catch ratio results. In the present study, the calculated catch ratio values on an array of cubic buildings are compared with measurements from two rain events with different characteristics. It is found that the numerical model estimates the WDR amounts and gradients over the facades successfully. The discrepancies between numerical and experimental results are lower for the first rain event where the rainfall is continuous and more homogeneous. On the other hand, the discrepancies in the catch ratio values at the end of the rain event are higher for the second rain event, during which the rainfall is interrupted many times. This result is to be expected given the guidelines for WDR measurements by Blocken and Carmeliet $[14,15]$.

The sources of error in a validation study can be numerical and experimental. Experimental errors are composed of (1) evaporation of droplets adhered to the collection area of the WDR gauge, (2) error due to the rest-water that remains in the tipping bucket, (3) splashing of drops from the collection area, (4) condensation on the collection area, and (5) wind errors due to the disturbances of the wind field and the raindrop trajectories near the WDR gauge by the presence of the gauge itself. The error estimation for the rain events is given in Kubilay et al. [3]. The numerical errors are composed of errors related to boundary conditions, inaccuracies of the model and numerical solutions. For the first rain event, even though the discrepancies are much lower, they are slightly above the error estimates (between $2.2 \%$ and 3.9\% [3]). For the second rain event, the deviations between numerical and experimental data are within the error estimates (between $14.8 \%$ and $32.3 \%$ [3]), except for the WDR gauge at the bottom left of the west facade of the cube 8.

\section{Conclusions}

This paper presented a study on the WDR catch ratio values using EM model with turbulent dispersion during two rain events on an array of low-rise cubic buildings. The catch ratio distributions on west facades of two of the nine low-rise cubic building models were compared with the existing measurement data. Both the WDR intensities at the end of the rain events and the cumulative WDR intensities matched quite well with the measured values. It was found that rain with oblique wind direction to the building orientation results in smaller gradients on the building facades, but also larger wetting on the whole building. For both rain events, the influence of turbulent dispersion was found to be lower than $3 \%$ for the low-rise cubic building models in this particular study. The EM model allows for the accurate estimations of catch ratio on all surfaces in the building configuration.

\section{Acknowledgements}

The research was supported through the Swiss National Science Foundation (SNF) - Project no. 135510. 


\section{References}

[1] Van Balen K. Expert system for evaluation of deterioration of ancient brick masonry structures. Sci Total Environ. 1996;189:247-254. [2] Franke L, Schumann I, van Hees R, van der Klugt L, Naldini S, Binda L, Baronio G, van Balen K, Mateus J. Damage atlas: classification and analyses of damage patterns found in brick masonry. European Commision Research report No 8, vol 2, Fraunhofer IRB Verlag. 1998.

[3] Kubilay A, Derome D, Blocken B, Carmeliet J. High-resolution field measurements of wind-driven rain on an array of low-rise cubic buildings. Build Environ. 2014;78:1-13.

[4] Erkal A, D'Ayala D, Sequeira L. Assessment of wind-driven rain impact, related surface erosion and surface strength reduction of historic building materials. Build Environ. 2012;57:336-348.

[5] Tang W, Davidson CI, Finger S, Vance K. Erosion of limestone building surfaces caused by wind-driven rain: 1. Field measurements. Atmos Environ. 2004;38:5589-5599.

[6] Charola AE, Lazzarini L. Deterioration of brick masonry caused by acid rain. ACS Symp Series 318. 1986:250-258.

[7] Davidson CI, Tang W, Finger S, Etyemezian V, Striegel M, Sherwood SI. Soiling patterns on a tall limestone building: changes over 60 years. Environ Sci Technol. 2000;34:560-565.

[8] Etyemezian V, Davidson CI, Zufall M, Dai W, Finger S, Striegel M. Impingement of rain drops on a tall building. Atmos Environ. 2000;34:2399-2412.

[9] Abuku M, Janssen H, Roels S. Impact of wind-driven rain on historic brick wall buildings in a moderately cold and humid climate: Numerical analyses of mould growth risk, indoor climate and energy consumption. Energ Buildings. 2009;41:101-110.

[10] Blocken B, Carmeliet J. A review of wind-driven rain research in building science. J Wind Eng Ind Aerodyn. 2004;92:1079-1130

[11] Blocken B, Carmeliet J. Overview of three state-of-the-art wind-driven rain assessment models and comparison based on model theory. Build Environ. 2010;45:691-703.

[12] Blocken B, Derome D, Carmeliet J. Rainwater runoff from building facades: A review. Build Environ. 2013;60:339-361.

[13] Blocken B. 50 years of Computational Wind Engineering: Past, present and future. J Wind Eng Ind Aerodyn. 2014;129:69-102.

[14] Blocken B, Carmeliet J. High-resolution wind-driven rain measurements on a low-rise building - experimental data for model development and model validation. J Wind Eng Ind Aerodyn. 2005;93:905-928.

[15] Blocken B, Carmeliet J. On the accuracy of wind-driven rain measurements on buildings. Build Environ. 2006;41:1798-1810.

[16] Högberg A, Kragh M, van Mook FJR. A comparison of driving rain measurements with different gauges. 5th Symposium of Building Physics in the Nordic Countries, Göteborg, Sweden. 1999. p. 361-368.

[17] Blocken B, Carmeliet J. Spatial and temporal distribution of driving rain on a low-rise building. Wind Struct. 2002;5:441-462.

[18] Blocken B, Dezso G, van Beeck J, Carmeliet J. The mutual influence of two buildings on their wind-driven rain exposure and comments on the obstruction factor. J Wind Eng Ind Aerodyn. 2009;97:180-196.

[19] Blocken B, Roels S, Carmeliet J. A combined CFD-HAM approach for wind-driven rain on building facades. J Wind Eng Ind Aerodyn. 2007;95:585-607.

[20] Janssen H, Blocken B, Roels S, Carmeliet J. Wind-driven rain as a boundary condition for HAM simulations: Analysis of simplified modelling approaches. Build Environ. 2007;42:1555-1567.

[21] Van den Brande T, Blocken B, Roels S. Rain water runoff from porous building facades: Implementation and application of a firstorder runoff model coupled to a HAM model. Build Environ. 2013;64:177-186.

[22] Choi ECC. Numerical simulation of wind-driven rain falling onto a 2-D building. Asia Pacific Conf. on Computational Mechanics, Hong Kong. 1991. p. 1721-1728.

[23] Choi ECC. Simulation of wind-driven-rain around a building. J Wind Eng Ind Aerodyn. 1993;46-47:721-729.

[24] Choi ECC. Determination of wind-driven-rain intensity on building faces. J Wind Eng Ind Aerodyn. 1994;51:55-69.

[25] Choi ECC. Modelling of wind-driven rain and its soil detachment effect on hill slopes. J Wind Eng Ind Aerodyn. 2002;90:10811097.

[26] Hangan H. Wind-driven rain studies. A C-FD-E approach. J Wind Eng Ind Aerodyn. 1999;81:323-331.

[27] van Mook FJR. Driving rain on building envelopes. Ph.D. thesis, Eindhoven University of Technology, Eindhoven, The Netherlands; 2002.

[28] Tang W, Davidson CI. Erosion of limestone building surfaces caused by wind-driven rain: 2. numerical modeling. Atmos Environ. 2004;38:5601-5609.

[29] Blocken B, Carmeliet J. The influence of the wind-blocking effect by a building on its wind-driven rain exposure. J Wind Eng Ind Aerodyn. 2006;94:101-127.

[30] Blocken B, Carmeliet J. Validation of CFD simulations of'wind-driven rain on a low-rise building facade. Build Environ. 2007;42:2530-2548

[31] Abuku M, Blocken B, Nore K, Thue JV, Carmeliet J, Roels S. On the validity of numerical wind-driven rain simulation on a rectangular low-rise building under various oblique winds. Build Environ. 2009;44:621-632.

[32] Briggen PM, Blocken B, Schellen HL. Wind-driven rain on the facade of a monumental tower: numerical simulation, full-scale validation and sensitivity analysis. Build Environ. 2009;44:1675-1690.

[33] van Hooff T, Blocken B, van Harten M. 3D CFD simulations of wind flow and wind-driven rain shelter in sports stadia: Influence of stadium geometry. Build Environ. 2011;46:22-37.

[34] Mohaddes Foroushani SS, Ge H, Naylor D. Effects of roof overhangs on wind-driven rain wetting of a low-rise cubic building: A numerical study. J Wind Eng Ind Aerodyn. 2014;125:38-51.

[35] Huang SH, Li QS. Numerical simulations of wind-driven rain on building envelopes based on Eulerian multiphase model. J Wind Eng Ind Aerodyn. 2010;98:843-857.

[36] Kubilay A, Derome D, Blocken B, Carmeliet J. CFD simulation and validation of wind-driven rain on a building facade with an Eulerian multiphase model. Build Environ. 2013;61:69-81. 
[37] Kubilay A, Derome D, Blocken B, Carmeliet J. Numerical modeling of turbulent dispersion for wind-driven rain on building facades. Environ Fluid Mech. 2014:1-25.

[38] Yakhot V, Orszag SA, Thangam S, Gatski TB, Speziale CG. Development of turbulence models for shear flows by a double expansion technique. Physics of Fluids A: Fluid Dynamics. 1992;4:1510-1520.

[39] de Wolf DA. On the Laws-Parsons distribution of raindrop sizes. Radio Sci. 2001;36:639-642.

[40] Boussinesq J. Essai sur la théorie des eaux courantes. Mémoires présentés par divers savants à l'Académie des Sciences. 1887;23:1680 .

[41] Best AC. The size distribution of raindrops. Quarterly Journal of the Royal Meteorological Society. 1950;76:16-36.

[42] Blocken B, Carmeliet J, Stathopoulos T. CFD evaluation of wind speed conditions in passages between parallel buildings - effect of wall-function roughness modifications for the atmospheric boundary layer flow. J Wind Eng Ind Aerodyn. 2007;95:941-962.

[43] Blocken B, Stathopoulos T, Carmeliet J. CFD simulation of the atmospheric boundary layer: wall function problems. Atmos Environ. 2007:41:238-252.

[44] Hargreaves DM, Wright NG. On the use of the k-epsilon model in commercial CFD software to model the neutral atmospheric boundary layer. J Wind Eng Ind Aerodyn. 2007;95:355-369.

[45] O'Sullivan JP, Archer RA, Flay RGJ. Consistent boundary conditions for flows within the atmospheric boundary layer. J Wind Eng Ind Aerodyn. 2011;99:65-77.

[46] Parente A, Gorle C, van Beeck J, Benocci C. Improved kappa-epsilon model and wall function formulation for the RANS simulation of ABL flows. J Wind Eng Ind Aerodyn. 2011;99:267-278.

[47] Richards PJ, Hoxey RP. Appropriate boundary conditions for computational wind engineering models using the k-€ turbulence model. J Wind Eng Ind Aerodyn. 1993;46-47:145-153.

[48] Tominaga Y, Mochida A, Yoshie R, Kataoka H, Nozu T, Yoshikawa M, Shirasawa T. AIJ guidelines for practical applications of CFD to pedestrian wind environment around buildings. J Wind Eng Ind Aerodyn. 2008;96:1749-1761.

[49] Franke J, Hellsten A, Schlunzen KH, Carissimo B. The COST 732 Best practice guideline for CFD simulation of flows in the urban environment: a summary. Int J Environ Pollut. 2011;44:419-427.

[50] Launder BE, Spalding DB. The numerical computation of turbulent flows. Comput Methods Appl Mech Eng. 1974:269-289.

[51] Cebeci T, Bradshaw P. Momentum transfer in boundary layers. New York: Hemisphere Publishing Corporation; 1977.

[52] Wieringa J. Updating the Davenport roughness classification. J Wind Eng Ind Aerodyn. 1992;41:357-368.

[53] Gunn R, Kinzer GD. The terminal velocity of fall for water droplets in stagnant air. J Meteorol. 1949;6:243-248.

[54] Blocken B, Carmeliet J. On the errors associated with the use of hourly data in wind-driven rain calculations on building facades. Atmos Environ. 2007;41:2335-2343.

[55] Pope SB. Turbulent flows: Cambridge University Press; 2000.

[56] Defraeye TWJ. Convective heat and mass transfer at exterior building surfaces. Ph.D. thesis, Katholieke Universiteit Leuven, Leuven, Belgium.; 2011.

[57] OpenCFD Ltd. OpenFOAM v2.2.2 User guide openfoam. 2013. 


\section{Figures}

a)

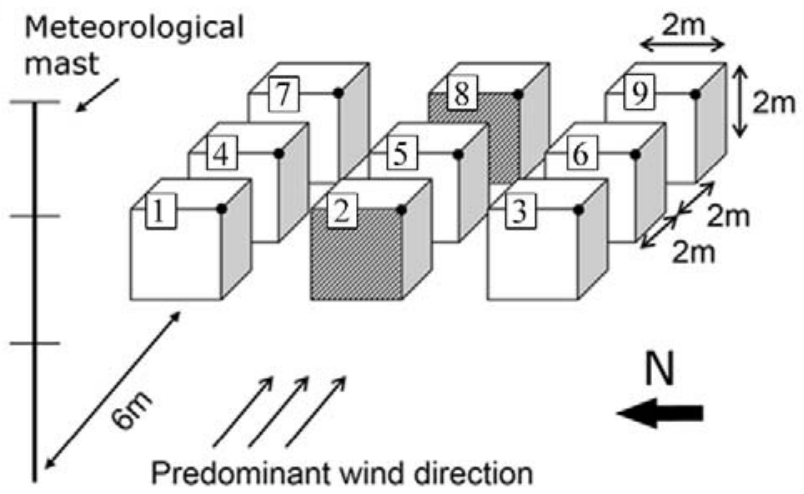

b)

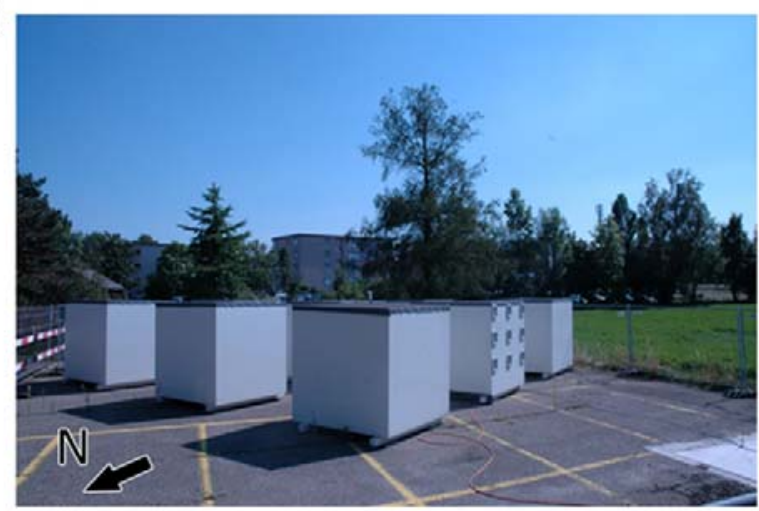

Fig. 1. a) Geometry of regular array of cubic building models. The WDR measurements are conducted on the grey facades. b) View from northwest of the measurement site.
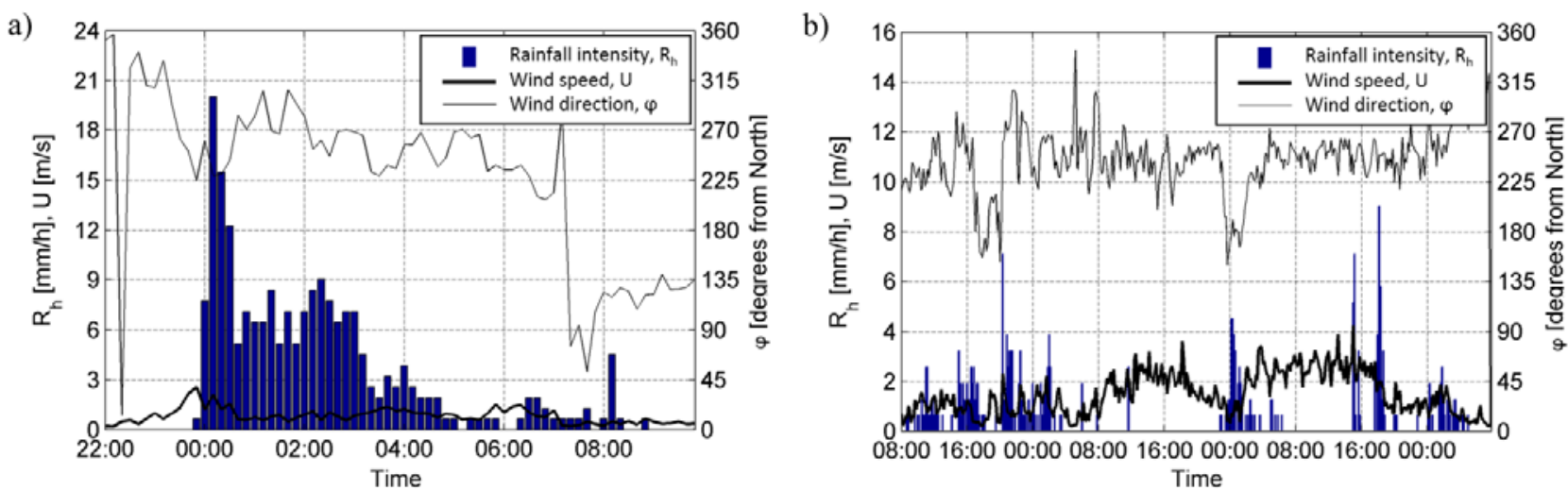

Fig. 2. 10-minute meteorological data for the rain event on a) June 9-10, 2013 and b) September 16-19, 2013. The wind speed displayed refers to the measurements at $2.4 \mathrm{~m}$ height.

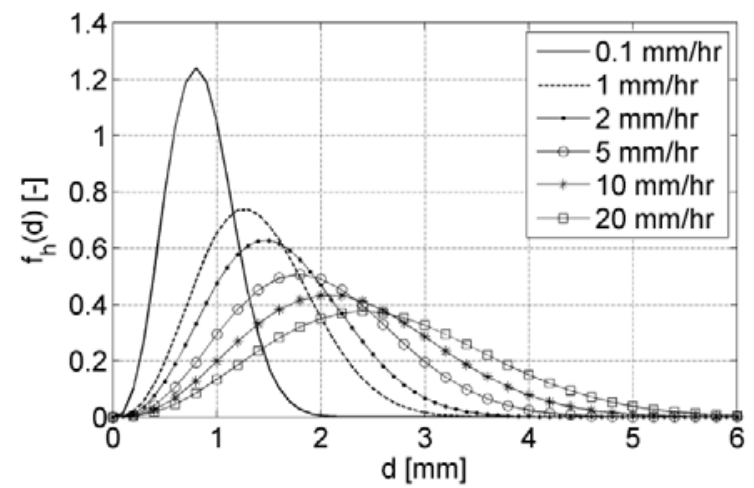

Fig. 3. Raindrop-size distributions through a horizontal plane for different rainfall intensities, calculated from raindrop-size distribution in the air according to Best [41]. 
a)

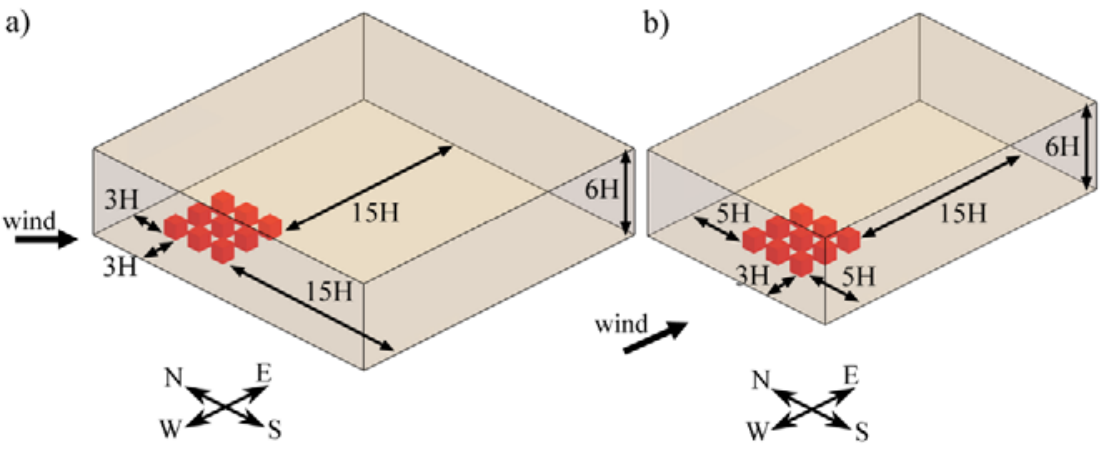

c)

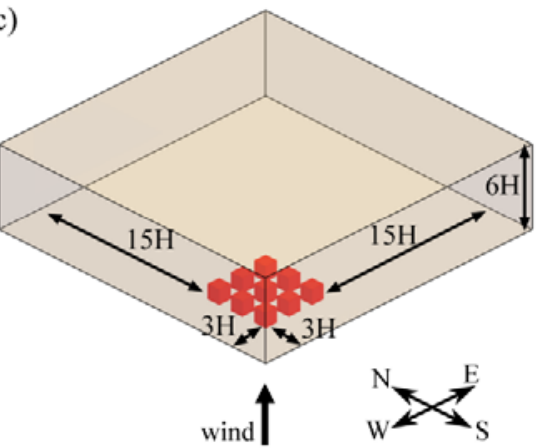

Fig. 4. The computational domain for wind from a) northwest, b) west and c) southwest. 
a)

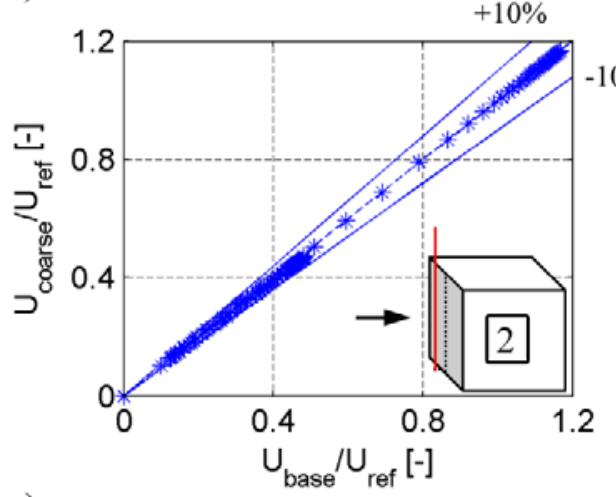

c)

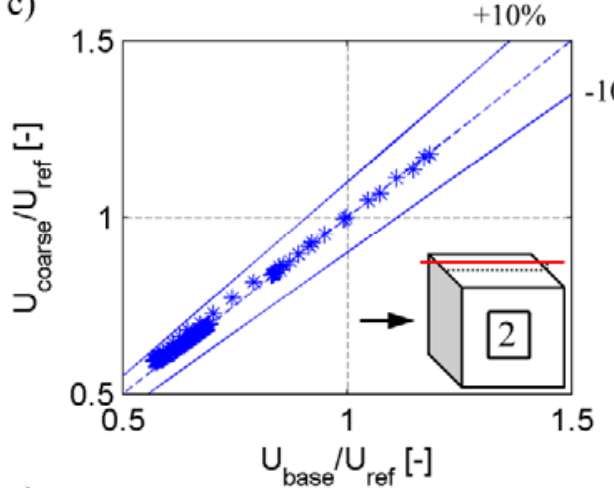

e)

e) $+10 \%$

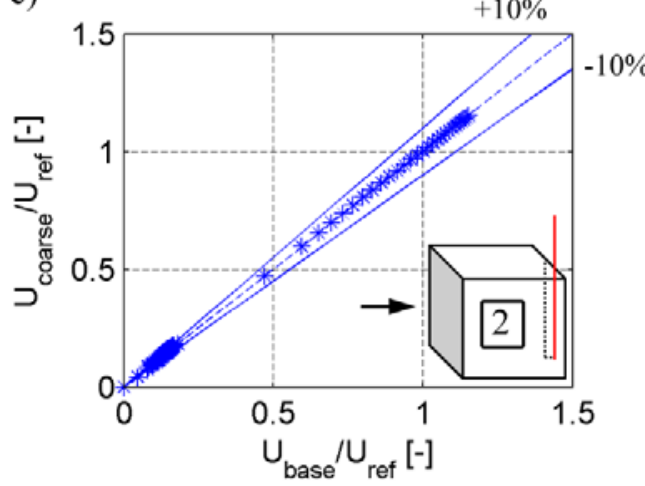

b)

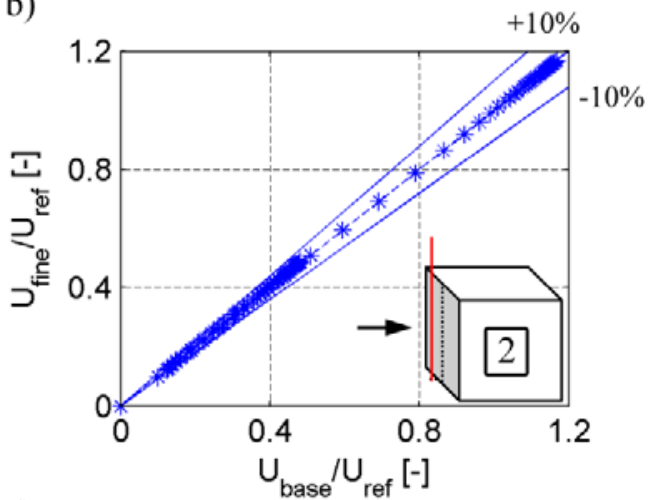

d)
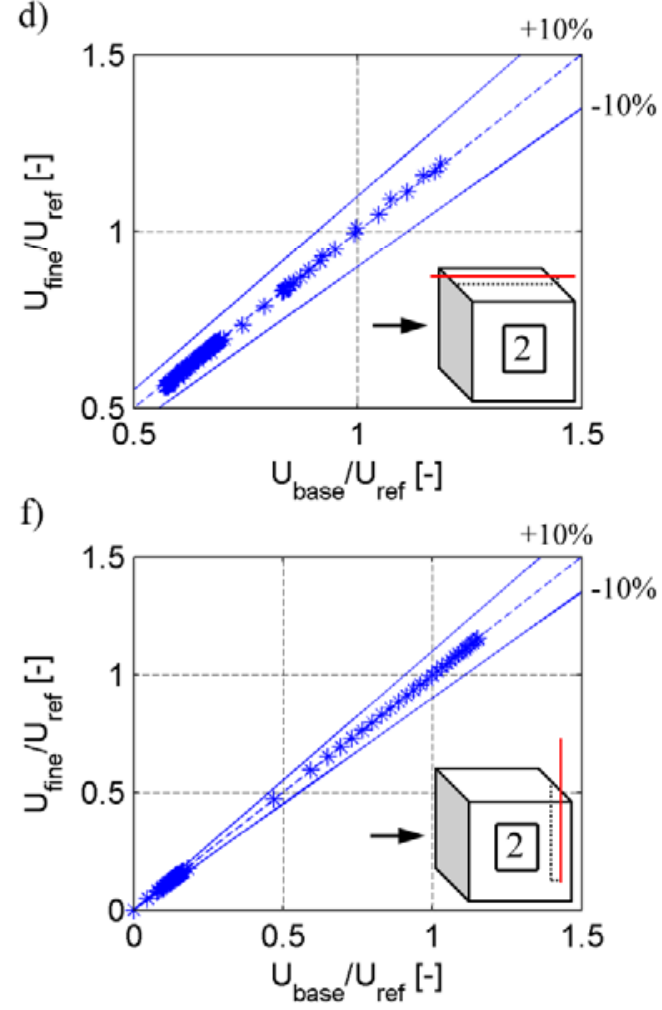

Fig. 5. Grid-sensitivity analysis comparing results for normalized magnitude of wind velocity on three different grids (coarse, base, fine) along lines positioned a-b) upstream of, c-d) above the roof of and e-f) downstream of cube 2 all in the centerplane. 


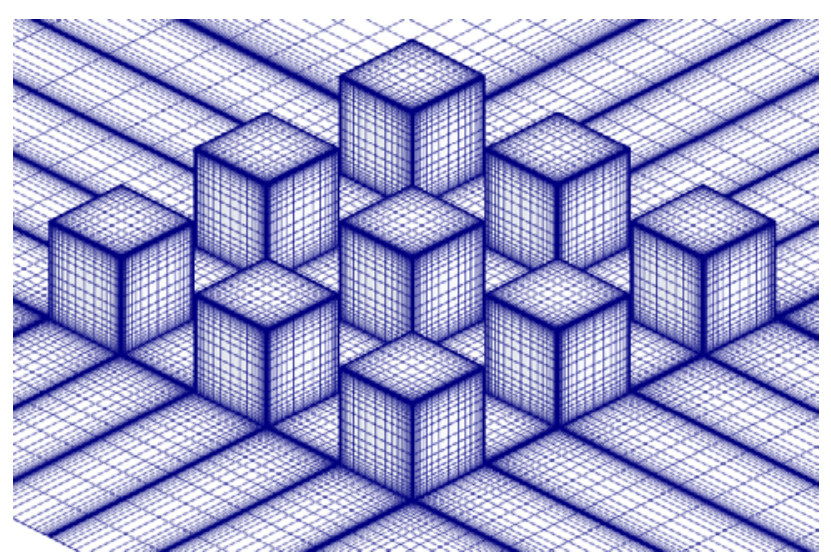

Fig. 6. Computational grid on the buildings and on part of the ground surface $(1,341,662$ cells).

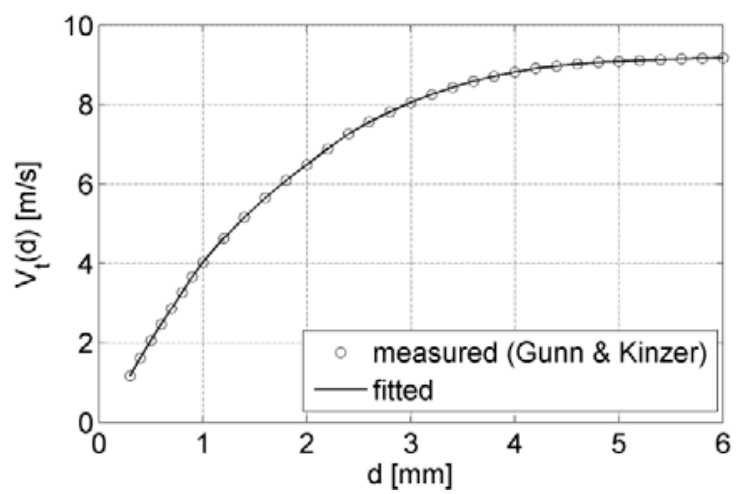

Fig. 7. Terminal velocity for raindrops - measurements by Gunn and Kinzer [53]. 

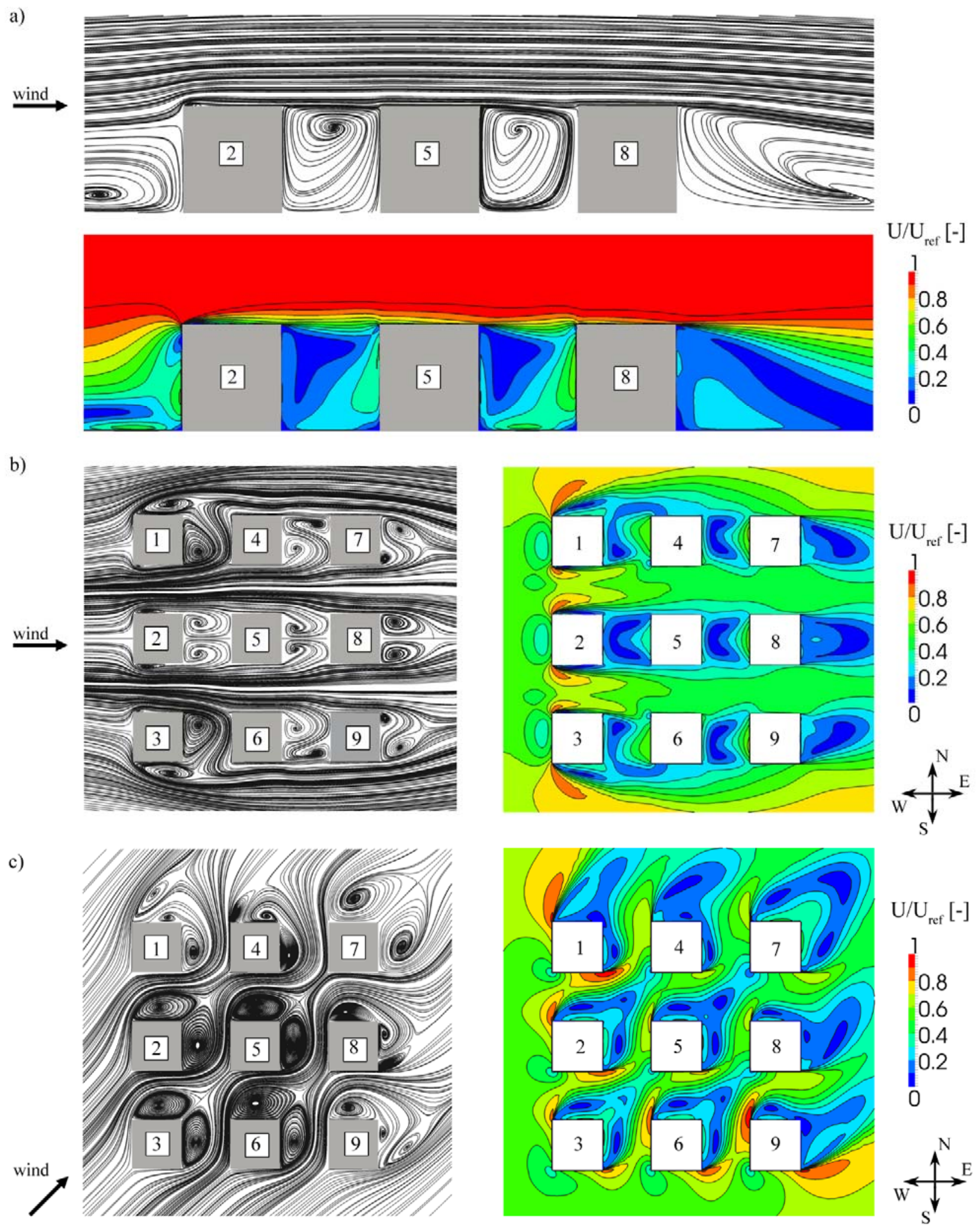

Fig. 8. Streamlines and contour plot of the wind flow in the a) vertical centerplane for wind from west, b) horizontal plane at $y=1 \mathrm{~m}$ height for wind from west, c) horizontal plane at $y=1 \mathrm{~m}$ height for wind from southwest. Streamlines in b) and c) are projected on the horizontal plane and hence have no out-of-plane component. 
a)

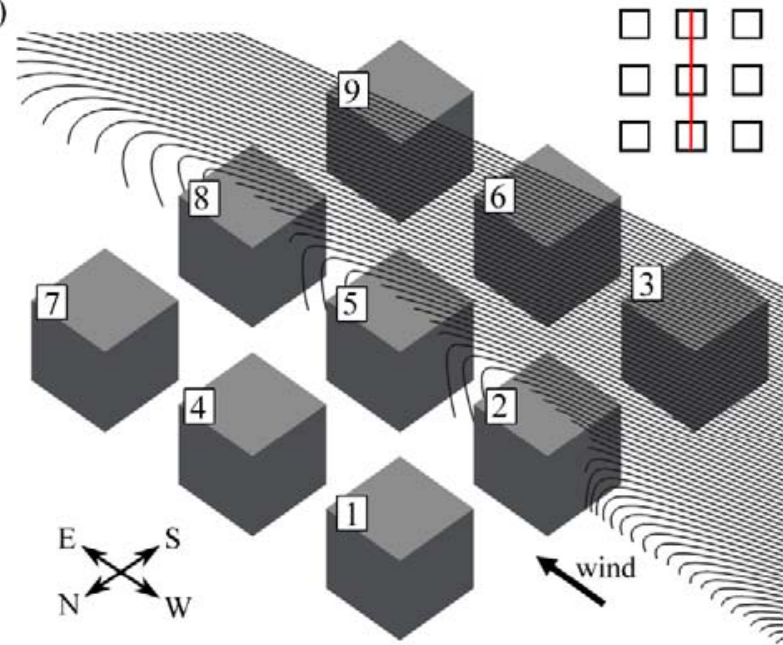

c)

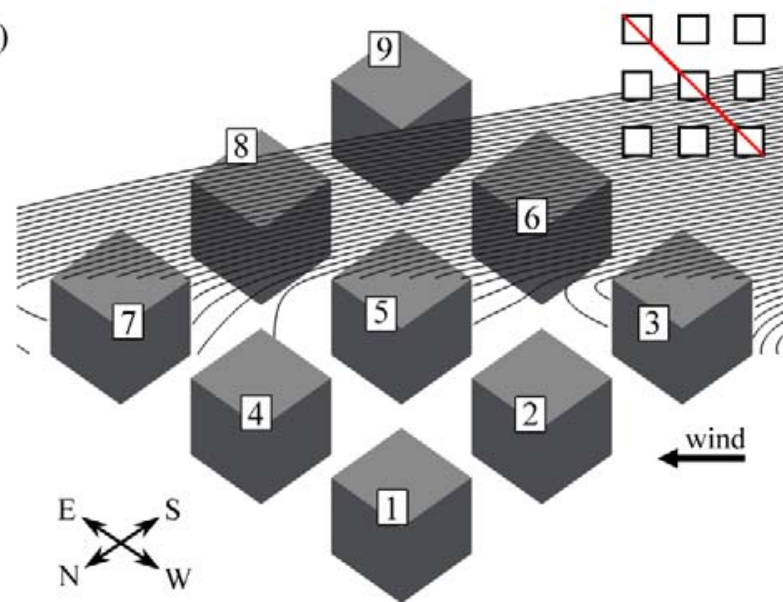

b)

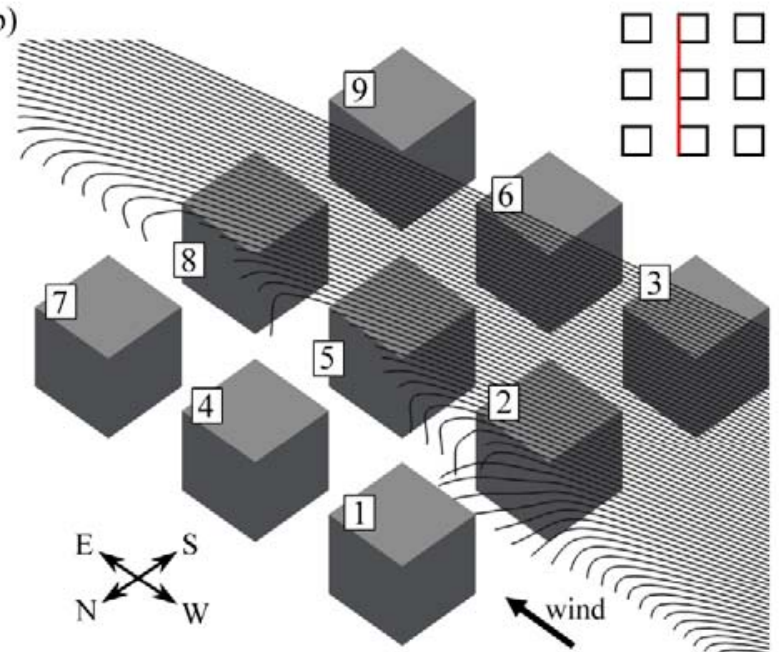

d)

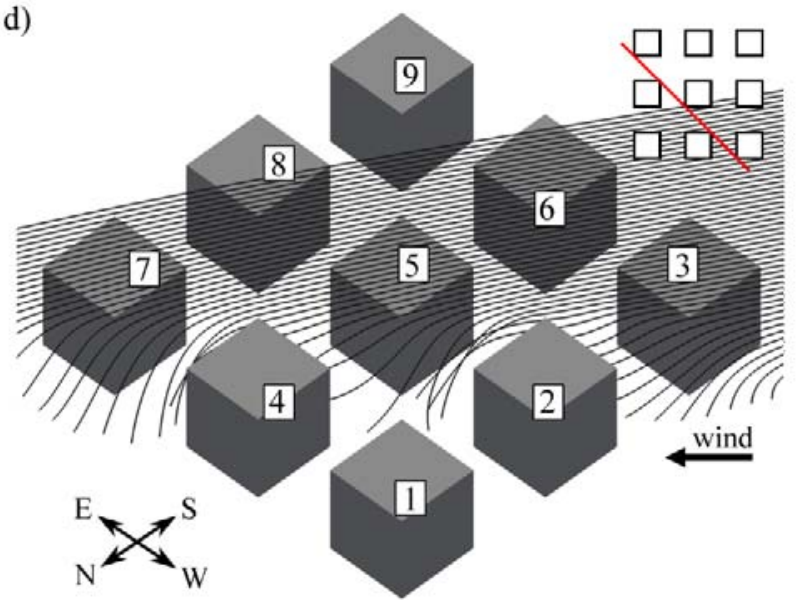

Fig. 9. Streamlines of rain phase for raindrop size $d=0.3 \mathrm{~mm}$ at reference wind speed $U=3 \mathrm{~m} / \mathrm{s}$ passing through two vertical lines at the inlet for wind from a)-b) west and c)-d) southwest. The droplets move in the direction indicated by the red line.

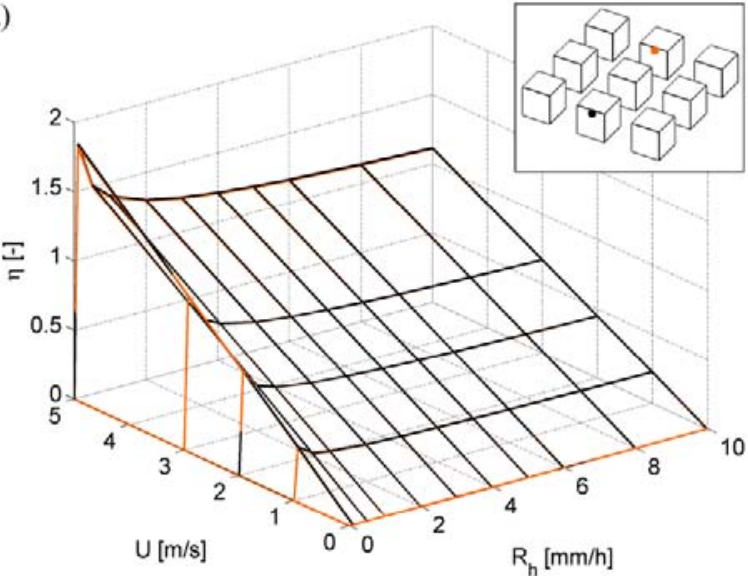

b)

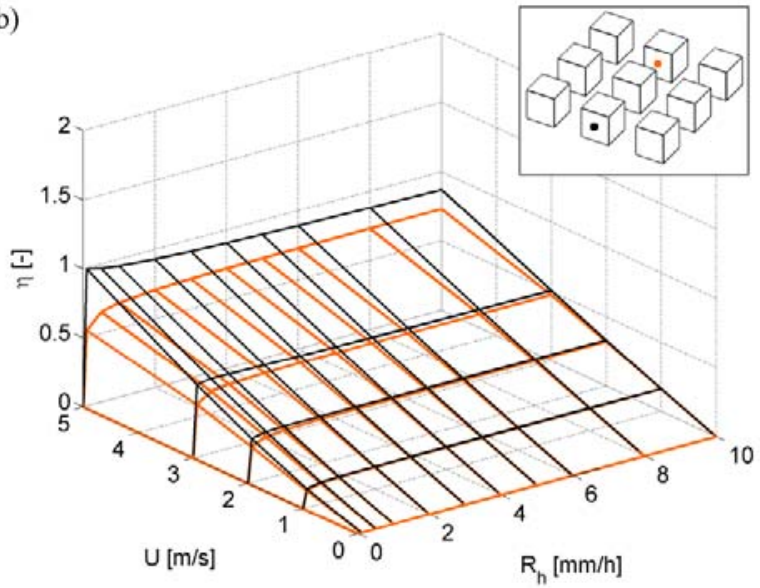

Fig. 10. Comparison of catch ratio charts for wind from west at positions a) at the top edge and b) at the center of the west facades of the cubes 2 and 8. 

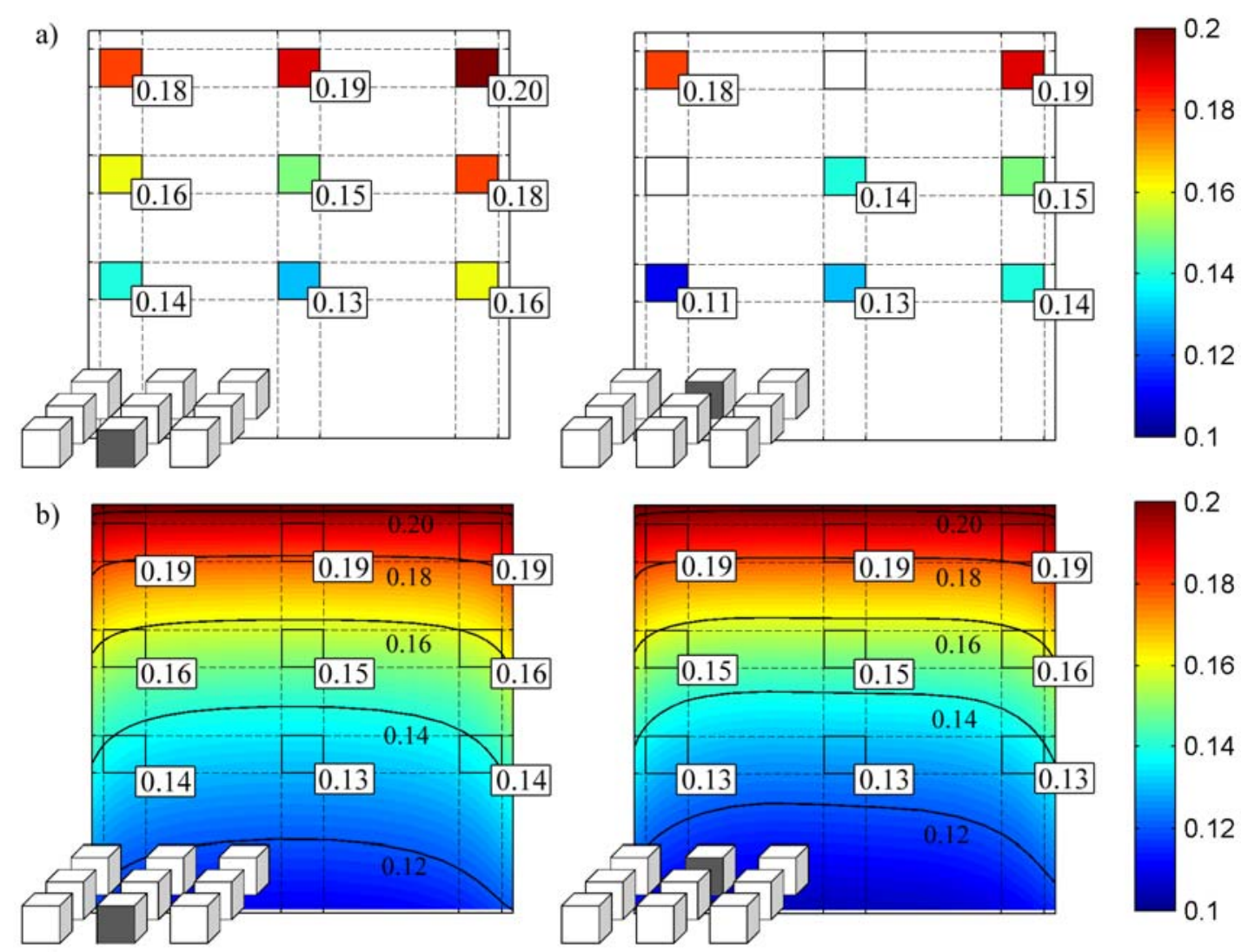

c)
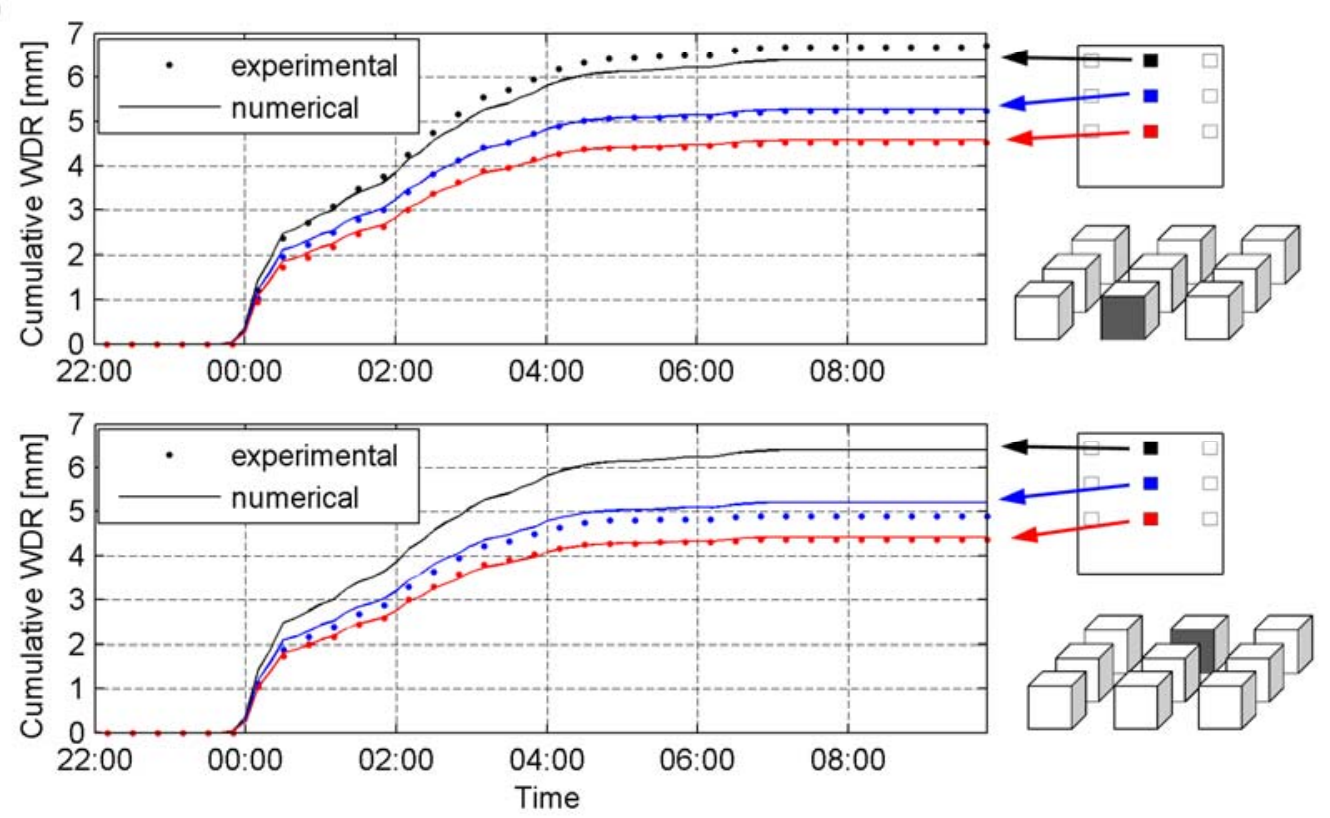

Fig. 11. Comparison of a) experimental and b) numerical catch ratio data on the west facades of the cubes 2 and 8 after the rain event on June 9-10, 2013. c) Comparison of cumulative WDR amounts on the cubes 2 and 8 during the rain event on June 9-10, 2013. 

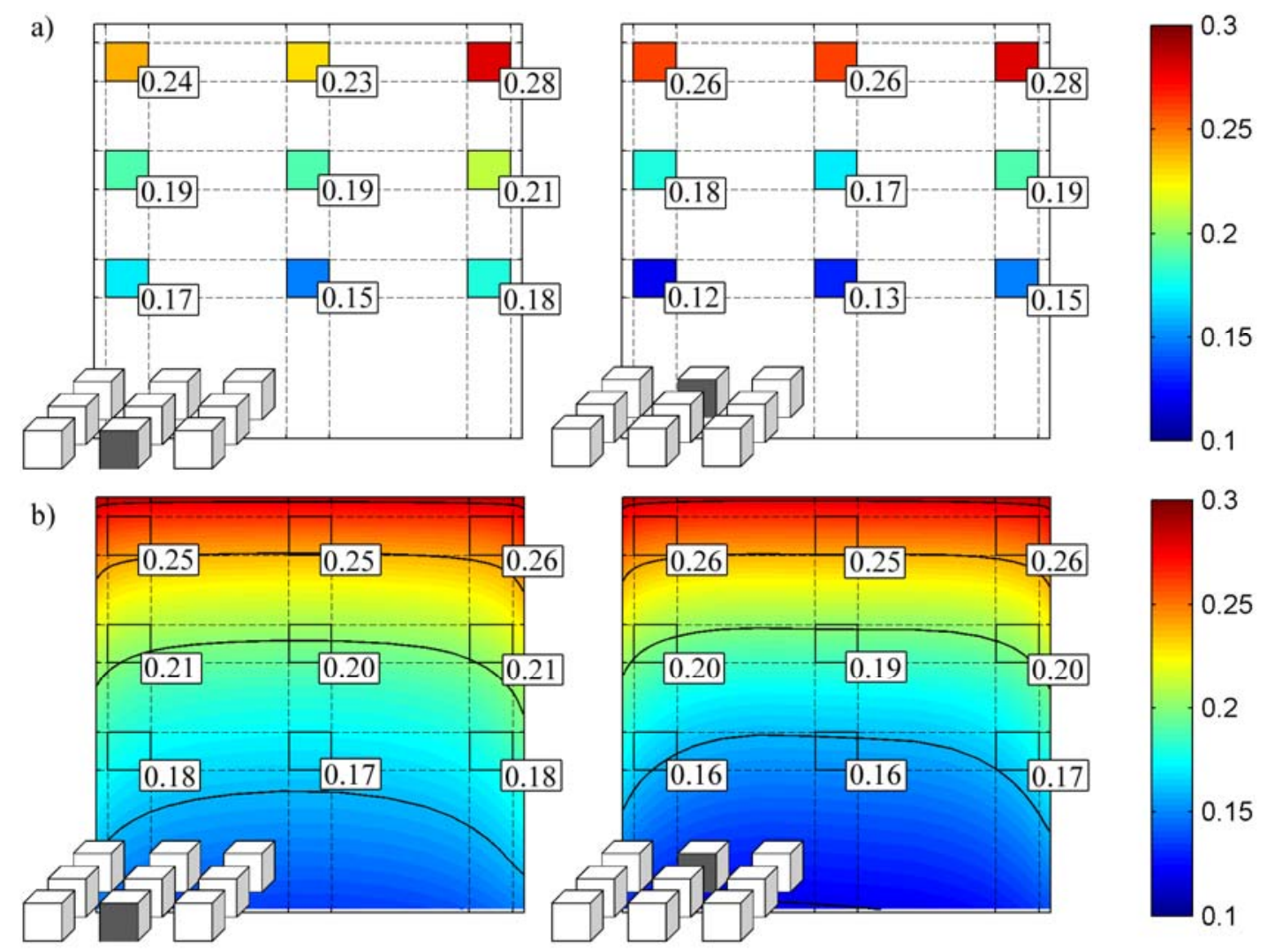

c)
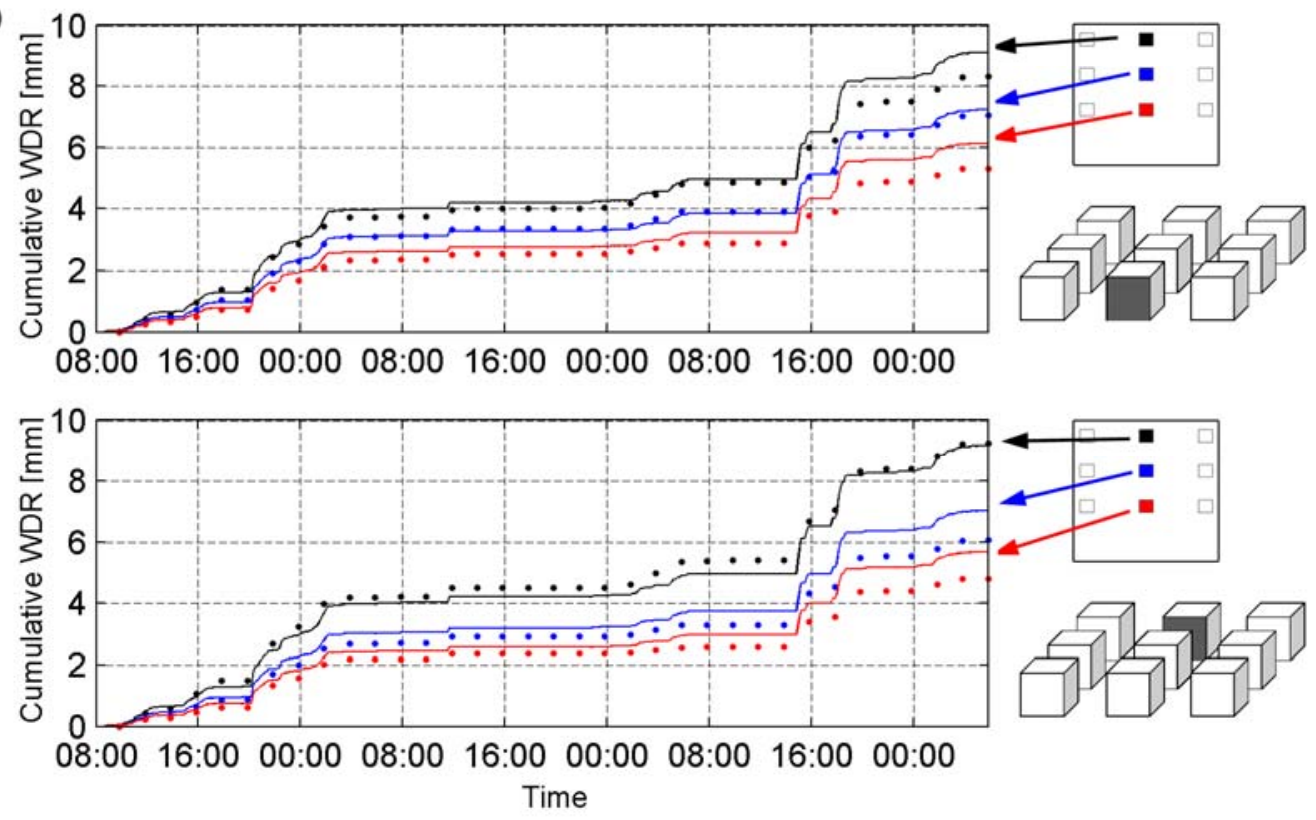

Fig. 12. Comparison of a) experimental and b) numerical catch ratio data on the west facades of the cubes 2 and 8 after the rain event on September 16-19, 2013. c) Comparison of cumulative WDR amounts on the cubes 2 and 8 during the rain event on September 16-19, 2013. 

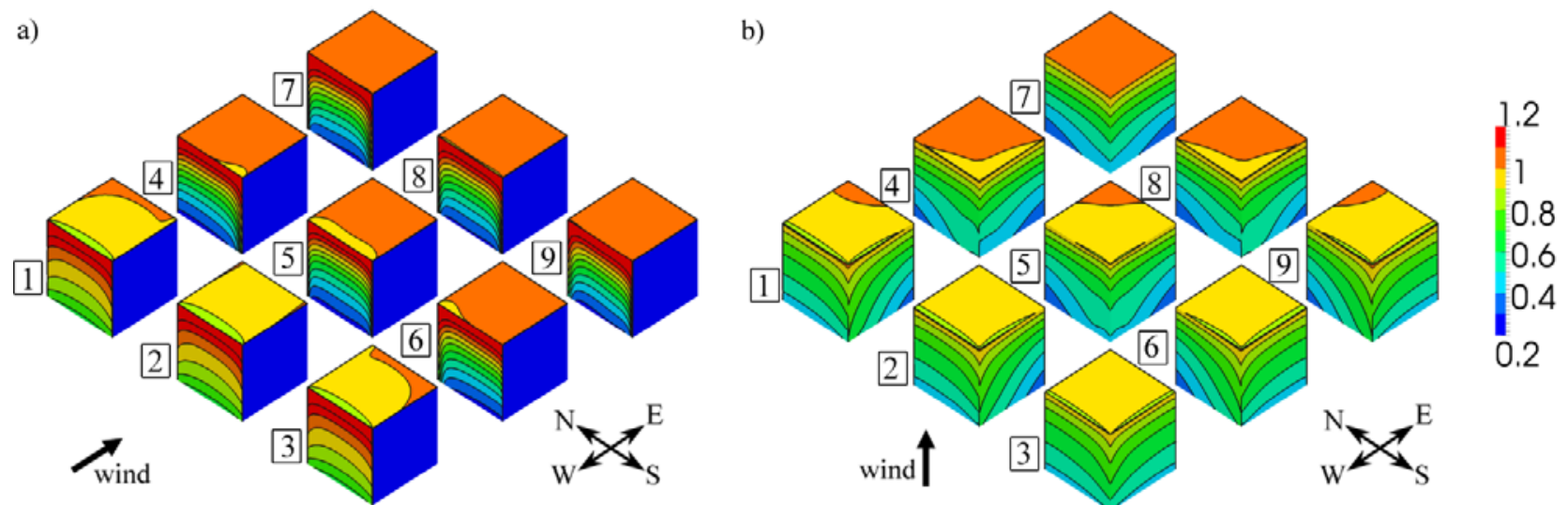

Fig. 13. Catch ratio distribution on facades and roofs of all cubes for the reference wind speed $U=5 \mathrm{~m} / \mathrm{s}$ and the reference rainfall intensity $R_{h}=1 \mathrm{~mm} / \mathrm{h}$ for wind from a) west and b) southwest.

a)

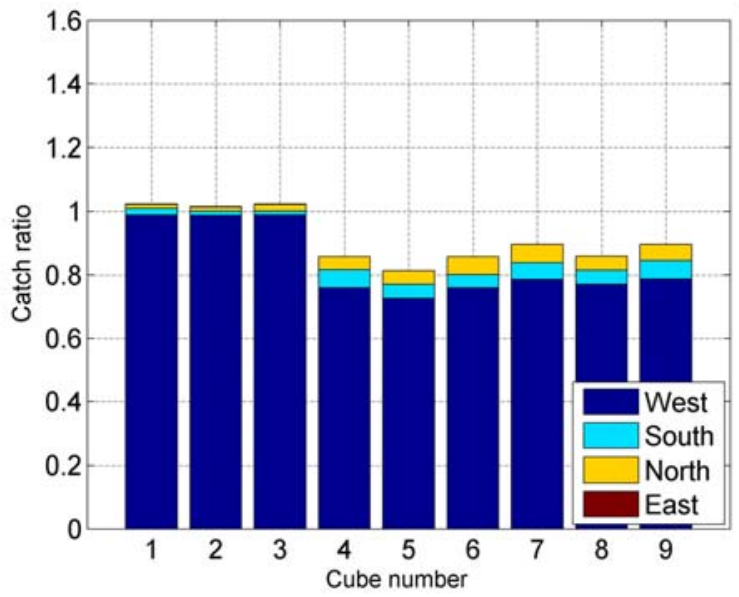

b)

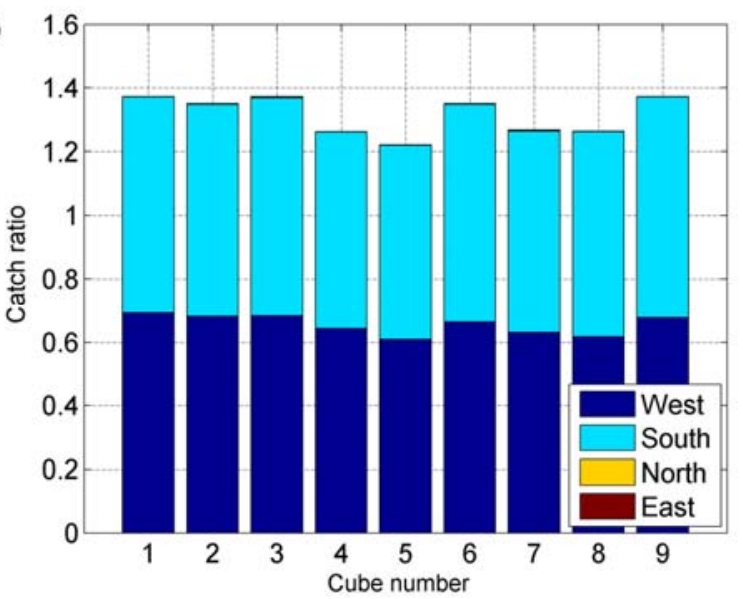

Fig. 14. Averaged catch ratio over facades of the cubes for the reference wind speed $U=5 \mathrm{~m} / \mathrm{s}$ and the reference rainfall intensity $R_{h}=1 \mathrm{~mm} / \mathrm{h}$ for wind from a) west and b) southwest. 